\title{
The Role of Dispensing by Japanese Community Pharmacists in Reducing Medicine Costs
}

\author{
Msayuki Yokoi ${ }^{1,2} \&$ Takao Tashiro ${ }^{2}$ \\ ${ }^{1}$ Pascal Pharmacy, Kusatsu, Japan \\ ${ }^{2}$ School of Graduate Studies, The Open University of Japan, Chiba, Japan \\ Correspondence: Masayuki Yokoi, Japan. 1-11-16 Oji, Kusatsu, Shiga 525-0032 Japan, Tel: 81-77-562-9354. \\ E-mail: pascal@nike.eonet.ne.jp
}

Received: December 26, 2016 Accepted: January 24, 2017 Online Published: February 6, 2017

doi:10.5539/gjhs.v9n3p248

URL: http://dx.doi.org/10.5539/gjhs.v9n3p248

\begin{abstract}
This study investigated the economic efficacy of separation of drug prescribing and dispensing (separation system). We examined whether daily medical expenses on prescriptions for former drugs, generic drugs, medical devices, and the number of drugs are curtailed due to the separation system, whose function is to separate the manager between prescribing and dispensing drug, and the effect of mutual check between prescribing doctors and dispensing pharmacists. Participation in the separation system is legally optional for Japanese medical institutions. It causes that the growth rate of the separation system in administrative districts is wide range. Furthermore, this study investigated the separation system in Japanese administrative districts with available open public data. We examined the separation system effect using National Healthcare Insurance data for 20112015. We tested whether the separation system growth rate for each Japanese administrative district was correlated to former drug significantly, generic drug, medical device price, and the number of drugs on prescriptions. The results show that growth of the separation system influenced the daily expense of prescribed former drugs and medical devices and the correlations were significant. Contrastively, the number of drugs and the expense of generic drugs on prescriptions were not significantly correlated with the separation system growth rate. Therefore, the separation system was effective at curtailing expenses of daily former drugs and medical devices but little effective at curtailing the number of daily drugs and generic drugs expense.
\end{abstract}

Keywords: expense, generic, drug, regression, separation system

\section{Introduction}

Annually increasing social security costs, such as medical nursing and pension expenses, are a common problem for developed nations, which typically have aging societies with low birthrates. Curtailing drug expenses was considered an important problem in Japan. As a countermeasure, in the 1960s, the Japanese government introduced an optional system to separate prescribing and dispensing drugs between doctors in medical institutions and pharmacists in pharmacies (hereafter, the separation system). For many years up to then in Japan, prescribed drugs were dispensed mainly by prescribing doctors in person.

Although Japanese government had the law of separation system since 1874, the organization of doctors, which had big political power, had strongly opposed to perform the law. The Japanese government compromised the organization by taking much budgetary measure for publishing the prescriptions and introducing the separation system optionally not forcibly in 1974. Thus, the Japanese government had managed to launch the separation system regularly since 1974 through a budgetary measure that was an impetus for the separation system.

There are several reports about the cost-effectiveness of interventions led by pharmacists around the world. For example, it has been found that community pharmacists can implement a cost-effective intervention to improve hypertension control in blacks (Shireman \& Svarstad, 2016). Another reports are that pharmacist participation in warfarin therapy management was a cost-effective intervention (Saokaew et al., 2013) and economic evaluations of clinical pharmacy services have been reported (Touchette et al., 2014). Furthermore, interventions by pharmacists have always been considered a valuable input by the healthcare community in patient care by reducing medication errors, rationalizing therapy, and reducing therapy costs (Al Rhabi, Al Sabri, \& Chitme, 2014). However, since the 1960s in Japan, debate has been ongoing about whether pharmacists' interventions in 
medical treatment curtailed drug expenses. It has been pointed out that most economic evaluations of clinical pharmacy intervention suffer from several methodological limitations relating to the absence of a control group without clinical pharmacy interventions (De Rijdt, Willems, \& Simoen, 2008).

It was suggested that the separation system was as effective in curtailing drug expenses as generic medicine usage (Yokoi \& Tashiro, 2014). The method of this study was to analyze the medical insurance data of every Japanese administrative district. As the Japanese government introduced the separation system optionally, the growth rate of the separation system differs among Japanese administrative wards, or local districts. Although the growth rate of the separation system across Japan was $63.1 \%$ in 2014 , it ranged from $35.2 \%$ to $83 \%$. Therefore, the correlation between the growth rate of the separation system and other factors was calculated by taking advantage of this local district data. As a result, a significant negative correlation was observed for the relationship between the growth rate of the separation system and daily internal drug expenses. This finding indicates that the separation system in Japan might contribute to curtailing daily drug expenses (Yokoi \& Tashiro, 2014).

In addition, a significant correlation between prescribed injections/medical devices and the growth rate of the separation system was continuously found. However, no significant correlation was found with external drug, such as patches or top-up drug. External drugs, like patches, are widely adopted by public insurance in Japan. Japanese patients can buy them at cheap expenses by using insurance. Thus, Japanese patients prefer having external drugs prescribed at medical institutions for purchase at drug stores, where drugs for sale are not object of the Japanese public insurance in the condition of not prescription. Under these circumstances, Japanese outpatients habitually intervene to have external drugs prescribed; for example, they request doctors or pharmacists to prescribe or dispense much more than is necessary. They often request external drugs, such as light painkiller patches for the knee, shoulder, waist, elbow, and joint pain, to keep as their own storage or for their family or acquaintances' using. The efficiency of these drugs is considered not so strong. Therefore, these prescriptions are easily influenced by patients' disposition toward such drugs. The patients' behavior of the market in the external drugs are similar to the behavior of the drug store market in terms of self-decisions. This might be a unique characteristic of the Japanese market. The Japanese government has begun to restrict the prescription of external drugs, like light painkiller patches, from public insurance since 2016. Thus, the economic efficiency effect for the separation of dispensing and prescribing could be weak owing to patients' disposition. This result coincides with the principle of the separation system. In the drug market, purchasers, namely, patients, cannot decide which drugs to purchase because of lack of medical know-how. Therefore, when doctors or medical institutions sell drugs, they also decide what patients should purchase. The principle of the separation system is to avoid the purchase of drugs by patients arising out of the circumstances of the seller (Yokoi \& Tashiro, 2015).

Continuously, it was researched the separation system effect by using the National Healthcare Insurance data for three years, 2012-2014. The study was reported that the growth rate of separation system for each administrative district was significantly correlated with the expense of drug but not the number of drugs per prescription. As a result, it was revealed that the growth rate of separation system did not influence with curtailing the number of drugs, but curtailing the price of each drugs (Yokoi \& Tashiro, 2016).

In this study, we aimed to establish the cause of curtailed prescribed daily drug costs more clearly, and to assess whether growth of the separation system acts to increase generic drugs, restrict high prices of new drugs or devices, or restrict the number of prescribed drugs.

\section{Method}

\subsection{Database}

In the Japanese legal system, a universal national health insurance system has been adapted to the Japanese situation. However, it is exceptions that those who were applied to welfare for livelihood protection, as medical expenses for needy people are paid from tax, not public insurance, by Japanese law. There are several public insurance providers and they are operated by local public bodies or occupational organizations through legislation. The Japanese Ministry of Health, Labour and Welfare (MHLW) usually provides totally combined insurance data for all public insurance providers. The Japanese government is divided into 47 administrative districts or prefectures. This database is anonymous data and totaling all data of Japanese health insurance system which is covered $99.9 \%$ Japanese people. The database opened the average data of each item of 47 administrative district or prefecture on the website of MHLW. This database is opened for actual circumstances of Japanese public health insurance system and analyzing freely. Therefore, ethical problem is little.

Within the prefectures are local governments. As Japanese prefectures and administrative districts (hereafter administrative districts) have local governments and their own original budgets and municipal regulations, they are 
akin to states in the United States (US) system of governance. However, their political and administrative power is not as strong as that of state governments of the US. Statistical data in Japan generally are organized and reported by administrative districts. Insurance data of administrative districts are collated annually from all insurance receipts submitted to each public insurance provider.

We can access the data of the MHLW website (Ministry of Health, Labour and Welfare [MHLW]) which has every fiscal year for community pharmacies.

Therefore, we can avail and analyze the data of all Japanese medical insurance. We obtained 2011-2015 fiscal data of the growth rate of the separation system of each administrative district in Japan from the database of the Japan Pharmaceutical Association (JPA) website. The growth rate of the separation system estimated by the JPA is calculated from the annual reports of combined Japanese public insurance data. It was calculated by the JPA that an estimated level of overall circulating prescription numbers anticipated in Japan, as mentioned by Yokoi and Tashiro (2015). The JPA made public the growth rate of the separating system for each Japanese 47 administrative districts on its website (Japan Pharmaceutical Association, 2011-2015). These data are recognized to be the formal growth rate of the separation system in Japan. We analyzed these data because the MHLW did not make public the data for the growth rate of the separation system.

As the table of the public price of drugs is legally added the price of new drugs every 4 months and rearrange totally every 2 years by the law of Japanese insurance system, it is very difficult to compare the economic efficacy before and after adoption of the separation system exactly. Therefore, in this study, we opted to use contemporary national data and analyze them by calculating the correlation with the growth rate of the separation system and other factors, that is, public health insurance data.

\subsection{Examination}

\subsubsection{Definition of Generic Drugs and Former Drugs}

We defined former drugs and generic drugs in order to identify whether the drug cost-reducing effect of the growth rate of the separation system increased the use of generic drugs. Generic drugs are legally defined in Japan. They have the same efficiency ingredients, usage, and dosage as former drugs. Several kinds of medical devices, for example, needles for self-injection and catheters, are legally prescribed on prescription and are available via public medical insurance. Therefore, medical devices were defined as medical devices available on legal prescriptions in Japan.

\subsubsection{Components of Total Medicine Cost}

Daily drug expense per prescription was determined by:

$$
T D=(F D+G D) \times N M+M D
$$

$T D$ : the total daily expense of drug on a prescription

$F D$ : the expense of daily former drug on a prescription

$G D$ : the expense of daily generic drug on a prescription

$N M$ : the number of prescribed daily drugs on a prescription

$M D$ : the expense of daily medical devices on a prescription

\subsubsection{Calculation for Examination}

We examined the separation system effect for curtailing the expense of each drug, device, or numbers of drugs on a prescription. We tested whether the separation system growth rate of each administrative district was significantly correlated with the average expense or number of the drugs on prescription. If the growth of the separation system affected the expense of daily prescribed drugs, devices, or number of drugs, the correlation between them would be significant. Therefore, we computed the correlation between the growth rate of the separation system and the daily generic drug price, daily former drug price, daily medical device, and number of prescribed drugs on a prescription. Data for 5 years (2011-2015) were analyzed. We used average expense in every administrative districts for each expense, which we obtained from the website of the MHLW. We investigated the single correlation as follows.

(A) the growth rate of the separation system versus the expense of former drugs per a day

(B) the growth rate of the separation system versus the expense of generic drugs per a day

(C) the growth rate of the separation system versus the expense of medical devices per a day 
(D) the growth rate of the separation system versus the number of prescribed drugs per a day

\subsubsection{Dependent Variables: Average Expense of Drug on Prescription}

We obtained 2011-2015 fiscal data for average drug expense and dosage days per prescription for each administrative district (MHLW, 2011-2015) in the same way that Yokoi and Tashiro (2014) did. Then, for each administrative district, we directly got from the database both the average daily expense of a drug per prescription (TD) and generic drugs (GD), medical devices (DC), and the number of daily drugs on a prescription (NM). The expense of daily former drugs (FD) was calculated by deducting (GD) from (TD).

$$
\mathrm{FD}=\mathrm{TD}-\mathrm{GD}
$$

Tables $1-3$ show the statistical parameters of the average daily expense of drugs as dependent variables availed in the data analysis from the 47 Japanese administrative districts over the 5 years of the study. The number of observations is the number of Japanese prefectures. Each expense is defined per prescription.

Table 1. Statistical Data for Daily Former Drug Expense (FD) (USD 1 cent $=1$ yen)

\begin{tabular}{lccccc}
\hline Fiscal year & 2011 & 2012 & 2013 & 2014 & 2015 \\
\hline $\mathrm{N}$ & 47 & 47 & 47 & 47 & 47 \\
Mean & 281.7 & 265.2 & 270.1 & 259.7 & 224.8 \\
Maximum & 324.6 & 305.1 & 312.0 & 302.2 & 270.7 \\
Minimum & 239.2 & 231.3 & 240.4 & 230.3 & 182.9 \\
Standard deviation & 19.1 & 18.0 & 18.2 & 18.3 & 20.8 \\
\hline
\end{tabular}

Table 2. Statistical Data for Daily Generic Drug Expense (GD) $($ USD 1 cent $=1$ yen)

\begin{tabular}{lccccc}
\hline Fiscal year & 2011 & 2012 & 2013 & 2014 & 2015 \\
\hline $\mathrm{N}$ & 47 & 47 & 47 & 47 & 47 \\
Mean & 27.4 & 30.9 & 35.8 & 41.1 & 46.8 \\
Maximum & 35.2 & 37.6 & 43.1 & 48.8 & 54.9 \\
Minimum & 21.8 & 25.2 & 29.6 & 34.8 & 40.1 \\
Standard deviation & 2.86 & 2.92 & 3.14 & 3.21 & 3.29 \\
\hline
\end{tabular}

Table 3. Statistical Data for Daily Medical Device Expense (MD) (USD 1 cent $=1$ yen)

\begin{tabular}{lccccc}
\hline Fiscal year & 2011 & 2012 & 2013 & 2014 & 2015 \\
\hline $\mathrm{N}$ & 47 & 47 & 47 & 47 & 47 \\
Mean & 0.74 & 0.73 & 0.73 & 0.73 & 0.73 \\
Maximum & 1.58 & 1.44 & 1.39 & 1.36 & 1.35 \\
Minimum & 0.30 & 0.32 & 0.33 & 0.37 & 0.39 \\
Standard deviation & 0.29 & 0.25 & 0.23 & 0.22 & 0.23 \\
\hline
\end{tabular}




\subsubsection{Dependent Variables: Number of Daily Prescribed Drugses (NM)}

We obtained 2011-2015 fiscal data of the average number of daily drugs per prescription for each Japanese administrative district (MHLW, 2011-2015). Table 4 shows the statistical parameters of the numbers of daily drugs as dependent variables availed in the data analysis from the 47 Japanese administrative districts.

Table 4. Statistical Data for the Number of Daily Drugs

\begin{tabular}{|c|c|c|c|c|c|}
\hline Fiscal year & 2011 & 2012 & 2013 & 2014 & 2015 \\
\hline $\mathrm{N}$ & 47 & 47 & 47 & 47 & 47 \\
\hline Mean & 2.95 & 2.95 & 2.95 & 2.93 & 2.91 \\
\hline Maximum & 3.26 & 3.25 & 3.23 & 3.19 & 3.16 \\
\hline Minimum & 2.67 & 2.67 & 2.67 & 2.66 & 2.64 \\
\hline Standard deviation & 0.14 & 0.14 & 0.14 & 0.14 & 0.13 \\
\hline
\end{tabular}

\subsubsection{Independent Variable: Growth Rate of Separation System}

The independent variable was the growth rate of the separation system. We got 2011-2015 fiscal data of the growth rate of the separation system among administrative districts in Japan. The JPA calculated the growth rate of the separation system estimated by statistics provided from the annual reports of the Insurance Association for Private Organizations and National Health Insurance, and an estimated level of overall prescription numbers anticipated in Japan. The JPA provided the growth rate of the separating system of each Japanese administrative districts on their website. In Japan, these data are recognized as the formal growth rate of the separation system. We used these data for single linear regression analysis as independent variables. Table 5 shows the statistical parameters of the growth rate of the separating system of each Japanese prefecture as independent variables. The number of observations equals the number of Japanese administrative districts.

Table 5. Statistical Data of the Growth Rate (\%) of the Separating System

\begin{tabular}{lccccc}
\hline Fiscal year & 2011 & 2012 & 2013 & 2014 & 2015 \\
\hline $\mathrm{N}$ & 47 & 47 & 47 & 47 & 47 \\
Mean & 63.1 & 64.3 & 65.4 & 67.2 & 68.6 \\
Maximum & 83.0 & 82.7 & 82.8 & 84.2 & 84.6 \\
Minimum & 35.2 & 37.8 & 40.7 & 45.0 & 47.2 \\
Standard deviation & 10.2 & 9.8 & 9.3 & 8.9 & 10.7 \\
\hline
\end{tabular}

\subsection{Data Analysis}

All statistical analyses were performed by single correlation and using the software Excel Statistics Bell Curve 2016 (Society Information Service Inc., Japan). We calculated the regression coefficients, constant, single regression coefficients (R), and p-values using the software. Each item of data, except for the number of Japanese administrative districts, dealt with three significant figures. The number of administrative districts dealt with an integral number naturally. 


\section{Results}

3.1 Single Correlation Analysis between Daily Former Medicine Price (FM) and Separation System Growth Rate

Table 6 shows the results of single correlation analysis between FD and the separation system growth rate. This table designates each single correlation coefficient $\mathrm{R}$ and p-values from 2011 to 2015 . Figure 1 depicts a scatter graph of FD and the growth rate of the separation system in 2015.

Table 6. Single Correlation for each Parameter between FD and the Separation System Growth Rate (\%)

\begin{tabular}{lllll}
\hline Fiscal year & Regression coefficient & Constant & $\begin{array}{l}\text { Single regression coefficient } \\
(\mathrm{R})\end{array}$ & $\mathrm{p}$-value \\
\hline 2011 & -0.918 & 339.7 & -0.513 & $\mathrm{p}<0.001$ \\
2012 & -0.839 & 319.1 & -0.475 & $\mathrm{p}<0.001$ \\
2013 & -0.895 & 328.6 & -0.479 & $\mathrm{p}<0.001$ \\
2014 & -1.002 & 327.0 & -0.509 & $\mathrm{p}<0.001$ \\
2015 & -1.268 & 311.7 & -0.539 & $\mathrm{p}<0.001$ \\
\hline
\end{tabular}

The results revealed a significant correlation between the daily expensed of former drug per prescription and the growth rate (\%) of the separation system. Each regression coefficient was negative and the $\mathrm{p}$-value was $\mathrm{p}<0.001$. Thus, the more the separation system grew, the lower was the drug expense on a prescription.

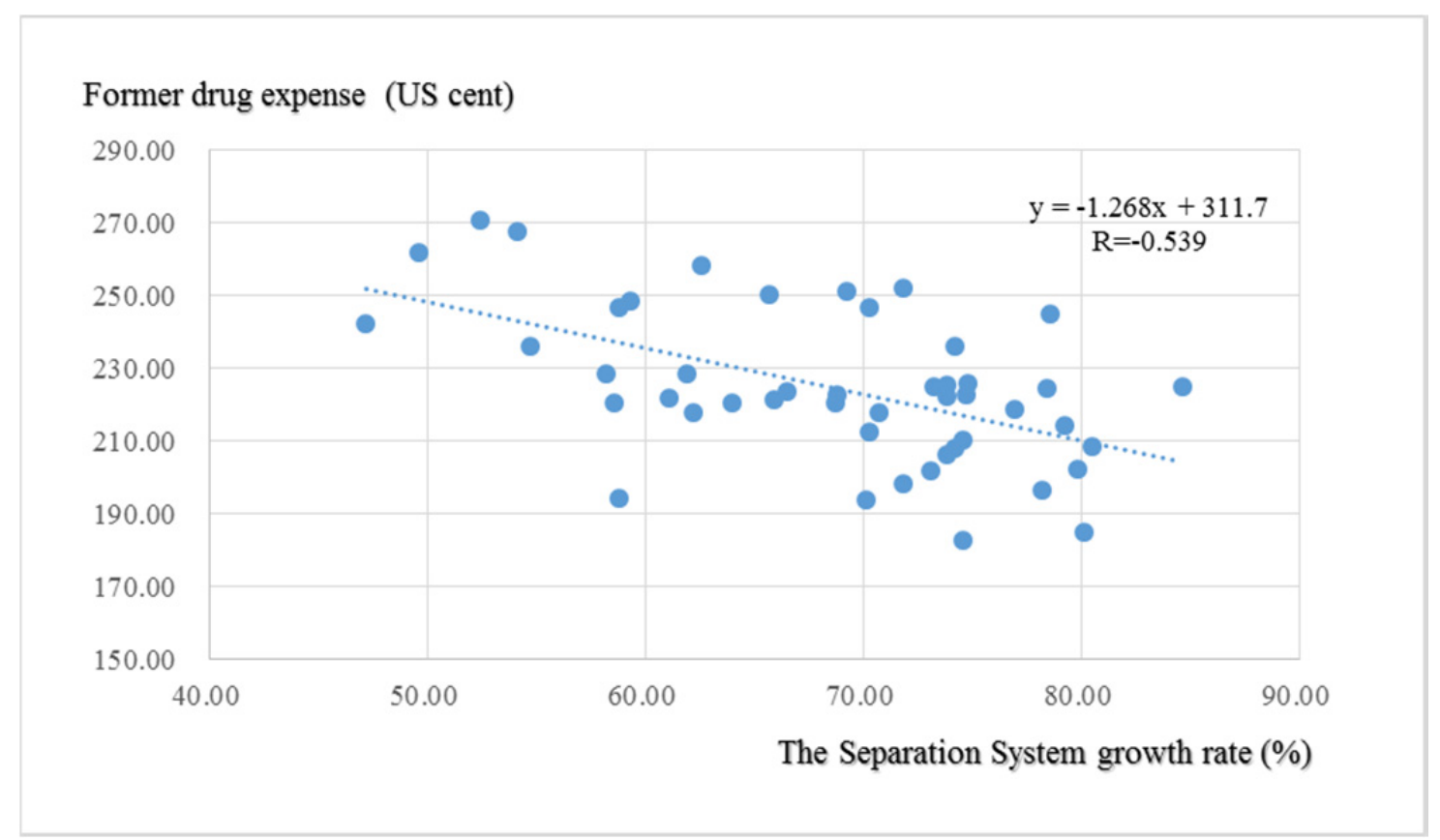

Figure 1. Scatter Graph of FD and the Separation System Growth Rate (\%) in 2015 


\subsection{Single Correlation Analysis between Daily Generic Drug Price (GD) and Separation System Growth Rate}

Table 7 shows the results of single correlation analysis between $G D$ and the separation system growth rate. Table 7 designates each single correlation coefficient $R$ and p-values from 2011 to 2015 . Figure 2 depicts a scatter graph of $G D$ and the separation system growth rate in 2015.

Table 7. Single Correlation for each Parameter between GD and the Separation System Growth Rate (\%)

\begin{tabular}{lllll}
\hline Fiscal year & Regression coefficient & Constant & $\begin{array}{l}\text { Single regression } \\
\text { coefficient }(\mathrm{R})\end{array}$ & $\mathrm{p}$-value \\
\hline 2011 & & & 0.0832 & $\mathrm{p}=0.578$ \\
2012 & 0.0224 & 26.0 & 0.0281 & $\mathrm{p}=0.851$ \\
2013 & 0.0080 & 30.4 & 0.0208 & $\mathrm{p}=0.890$ \\
2014 & 0.0067 & 35.3 & 0.1197 & $\mathrm{p}=0.423$ \\
2015 & 0.0413 & 38.3 & 0.0830 & $\mathrm{p}=0.579$ \\
\hline
\end{tabular}

The results revealed no significant correlation between the daily expense of generic drug per prescription and the growth rate of the separation system. Each p-value was much larger than 0.05 . There was no significant correlation between the daily expense of generic drug per prescription and the growth rate of the separation system. The correlation of the daily expense of generic drug per prescription with the separation system was much weaker than that of the daily expense of former drug. The separation system growth rate had little influence on the generic drug expense of a prescription.

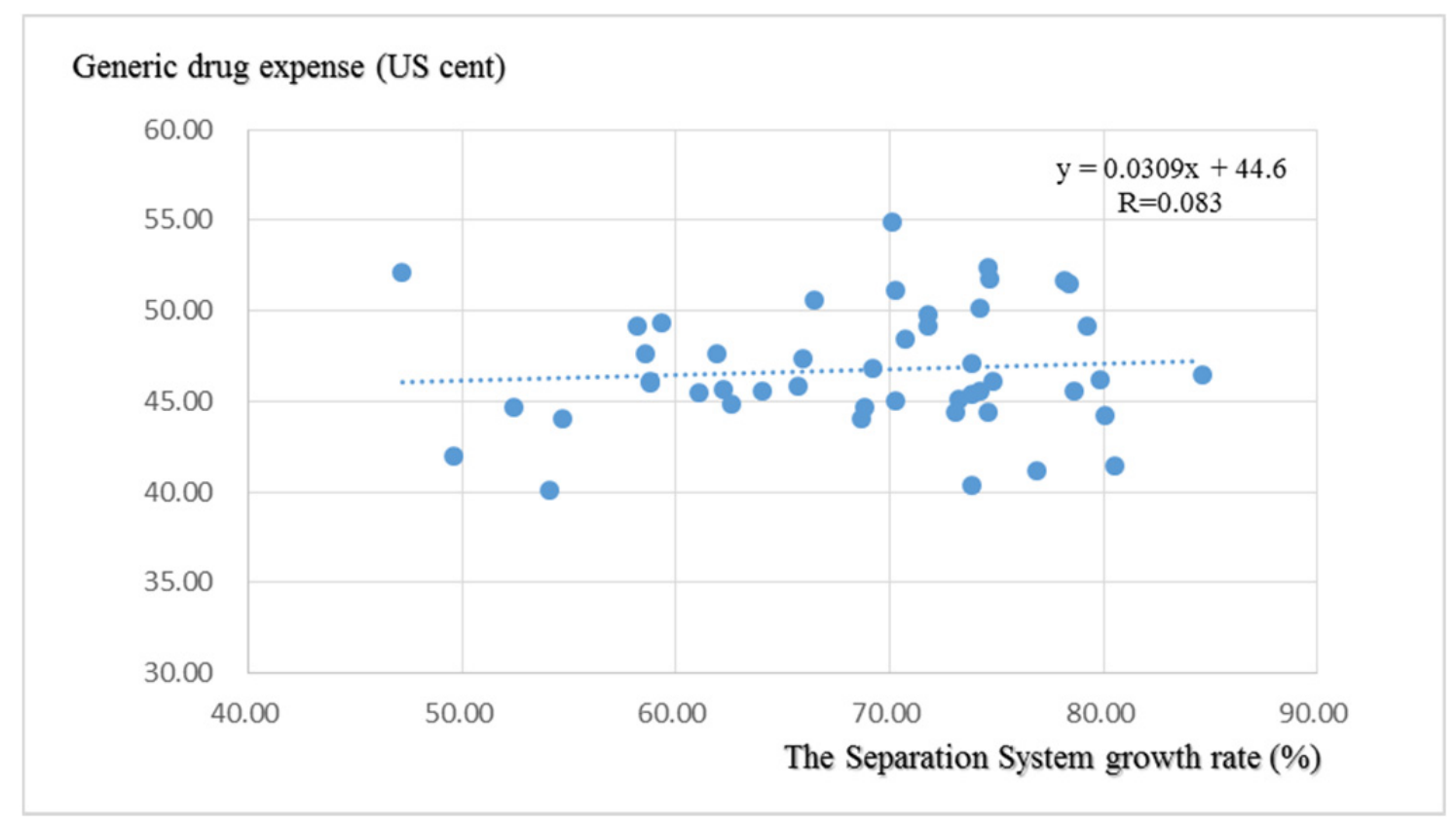

Figure 2. Scatter Graph of GM and the Separation System Growth Rate (\%) in 2015 
3.3 Single Correlation Analysis between Daily Medical Device Expense (MD) and Separation System Growth Rate

Table 8 shows the results of single correlation analysis between $M D$ and the separation system growth rate (\%). This table designates each single correlation coefficient $R$ and p-values from 2011 to 2015. Figure 3 depicts a scatter graph of $M D$ and the separation system growth rate (\%) in 2015.

Table 8. Single Correlation for each Parameter between $M D$ and the Separation System Growth Rate (\%)

\begin{tabular}{llclc}
\hline Fiscal year & $\begin{array}{l}\text { Regression } \\
\text { coefficient }\end{array}$ & Constant & $\begin{array}{l}\text { Single regression } \\
\text { coefficient (R) }\end{array}$ & $\mathrm{p}$-value \\
\hline 2011 & -0.0104 & 1.39 & -0.385 & $\mathrm{p}<0.01$ \\
2012 & -0.0089 & 1.30 & -0.354 & $\mathrm{p}<0.01$ \\
2013 & -0.0078 & 1.25 & -0.328 & $\mathrm{p}<0.05$ \\
2014 & -0.0086 & 1.30 & -0.357 & $\mathrm{p}<0.05$ \\
2015 & -0.0103 & 1.44 & -0.387 & $\mathrm{p}<0.01$ \\
\hline
\end{tabular}

The results designated a significant correlation between the daily price of medical devices per prescriptionand the growth rate of the separation system. All regression coefficients are negative and $p$-value is $p<0$. 05 . Thus, with the advance of the growth rate of the separation system, the medical device expense on a prescription is lower.

Medical device expense (US cent)

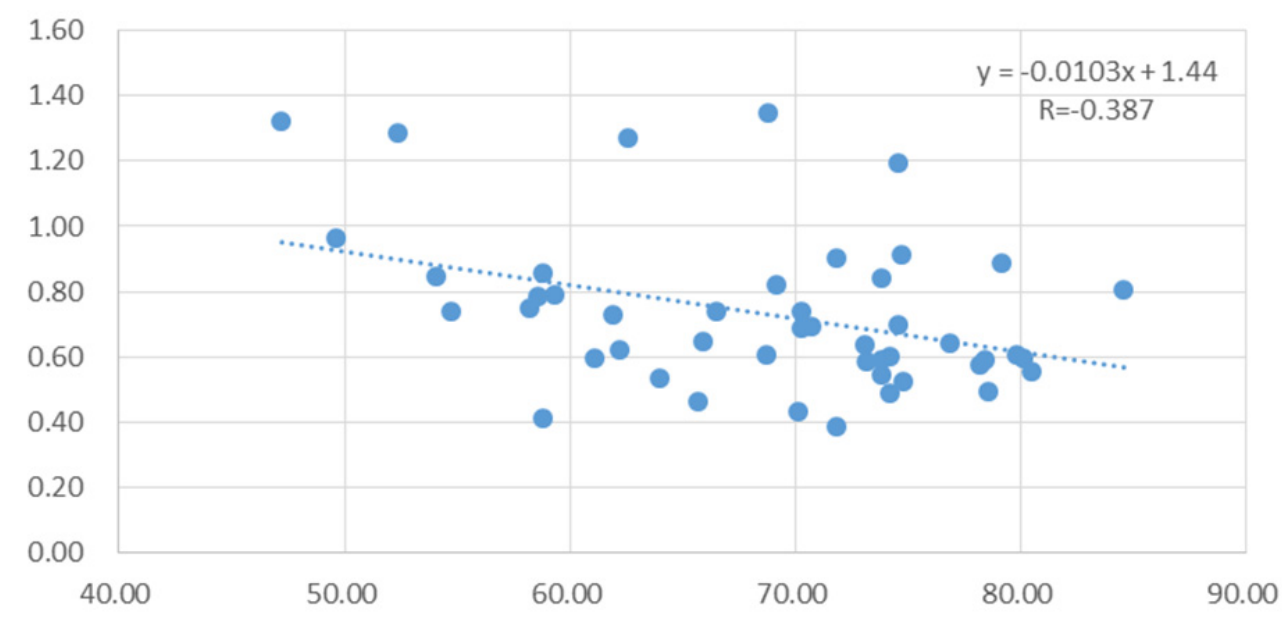

The Separation System growth rate (\%)

Figure 3. Scatter Graph of $M D$ and the Separation System Growth Rate (\%) in 2015 


\subsection{Single Correlation Analysis between Number of Daily Drug and Separation System Growth Rate}

Table 9 shows the results of single correlation analysis between $N M$ and the separation system ratio. This table designates each single correlation coefficient $R$ and p-values from 2011 to 2015. Figure 4 shows the scatter graph of $N D$ and the separation system growth rate in 2015.

Table 9. Single Correlation for each Parameter between NM and the Separation System Growth Rate (\%)

\begin{tabular}{lllll}
\hline Fiscal year & Regression coefficient & Constant & $\begin{array}{l}\text { Single regression } \\
\text { coefficient }(\mathrm{R})\end{array}$ & $\mathrm{p}$-value \\
\hline 2011 & & -0.254 & $\mathrm{p}=0.086$ \\
2012 & -0.00335 & 3.16 & -0.231 & $\mathrm{p}=0.118$ \\
2013 & -0.00321 & 3.15 & -0.225 & $\mathrm{p}=0.128$ \\
2014 & -0.00317 & 3.15 & -0.186 & $\mathrm{p}=0.211$ \\
2015 & -0.00270 & 3.12 & -0.187 & $\mathrm{p}=0.208$ \\
\hline
\end{tabular}

There was no significant correlation between the growth rate of the separation system and the number of daily medicines per prescription $(N D)$. Each p-value was much larger than 0.05 . The correlation of the numbers of drugs with the separation system was much weaker than that of the daily expense of former drugs or medical devices with the separation system. Therefore, the growth of the separation system had little influence on the numbers of daily drugs $(N D)$ on a prescription.

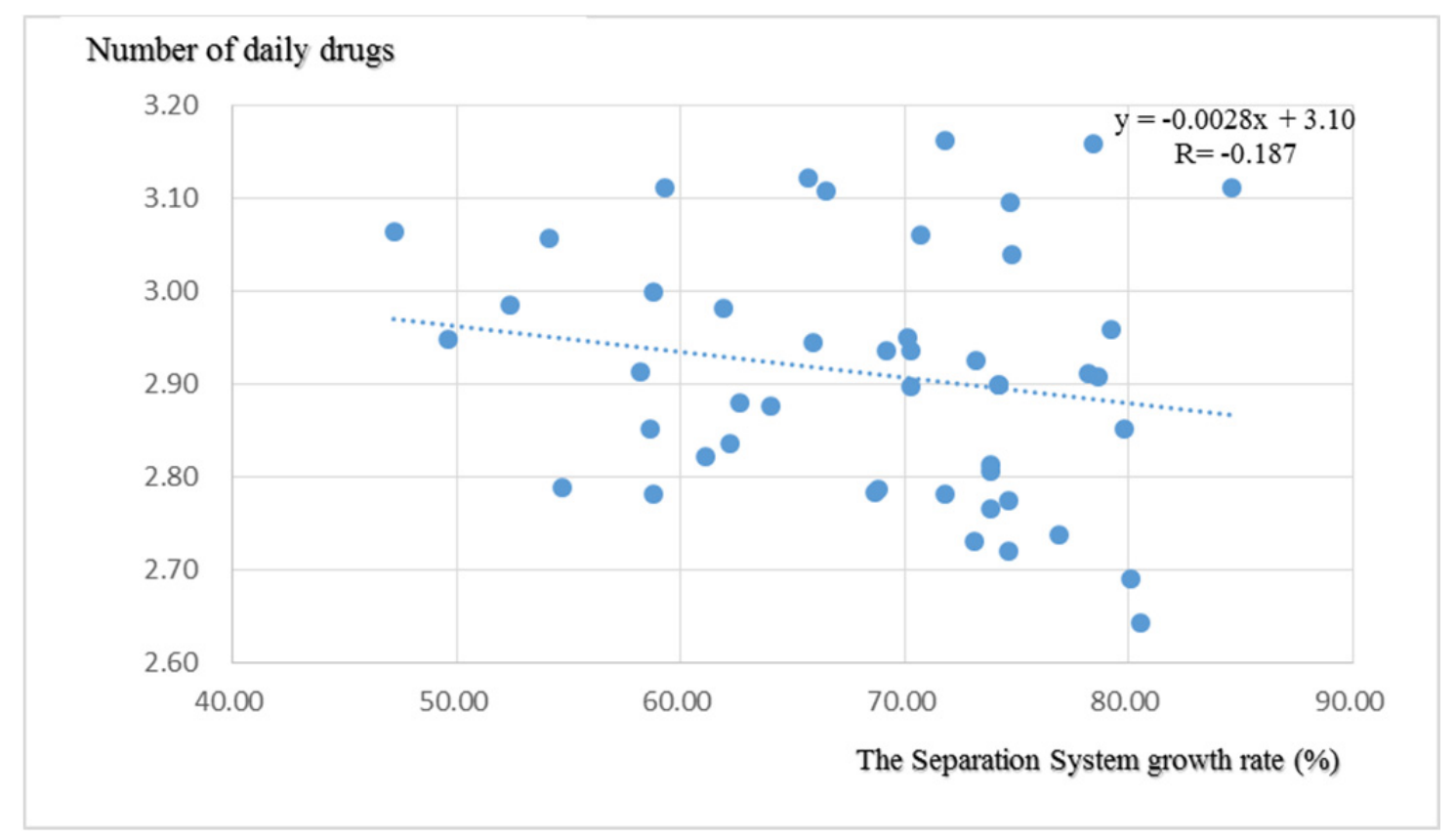

Figure 4. Scatter Graph of NM and the Separation System Growth Rate (\%) in 2015 


\section{Discussion}

We found that there was a significant correlation between the growth rate of the separation system and the daily expense of former drug $(F D)$ as well as the daily expense of medical devices $(M D)$. Contrastively, there was no significant correlation with the daily expense of generic drug $(G D)$ and the number of daily medicines $(N M)$ per prescription. This meant that the separation system influenced the reduction of expenses of former drugs and medical devices on a prescription. This was observed over the 5 years of the study period in Japan.

The growth of the separation system was effective in curtailing the expenses of daily former drugs and medical devices but had little influence on curtailing the number of daily drugs and the expenses of generic drugs. This result concerning medical devices coincided with previous research (Yokoi \& Tashiro, 2015)

If the separation system influenced doctors to prescribe better, the number of daily drugs per prescription would probably be curtailed as a result of removing unnecessary or harmful drugs. Although it was observed that the growth of the separation system had a tendency to curtail the number of prescribed drugs, there was no significant correlation between the growth of the separation system and the number of daily drugs (NM) per prescription when it was judged by risk at the 5\% level. We could not obtain clear evidence for such an influence in this study. This result coincided with previous research (Yokoi \& Tashiro, 2016)

The higher the growth rate of the separation system was, the more community pharmacies and pharmacists there were in the districts. Increasing community pharmacists in Japan are thought to influence not so much in the number of prescribed drugs but in the expense of former drugs. The cause of this result could not be determined in this research. Although it requires further research, we can guess the cause from the Japanese medicine market environment, besides the intrinsic function of the separation system.

We considered that the existence of many pharmacists' audits has caused increased hesitation by doctors to prescribe medications or devices with high public prices, and this is the cause of restricting the high prices of drugs or medical devices on prescription with the growth of the separation system. Furthermore, the sales people of pharmaceutical companies have been controlling the promotion of high prices of former drugs or medical devices to doctors, as a result of pharmacists' guidance of proper usage of prices. As community pharmacists substituted generic drug for former drug, it is considered that there was no significant correlation between the daily expense of generic drug (GD) and the growth rate of the separation system.

The public price of drug is determined at only $2 \%$ more than the weighted average of buying price of pharmacies by the rule of the Japanese price system of public health insurance (MHLW, 2016). Therefore, the profit of pharmacies is not so much influenced by the price of drugs. The profit of pharmacies is guaranteed by establishing settled charges under the name of technical fees. These technical fees are not influenced by the price of dispensing medications. The key result of this study is the important proof of this price system and the functioning of the separation system.

The reason for the number of daily drugs per prescription not being reduced is considered that to be restrained audit rights of Japanese pharmacists. Legally, they have only an inquiring right to ask prescribing doctors when they are in doubt, but not a compulsory right. The prescribing doctors must answer dispensing pharmacists' inquiries, but have no duty to obey pharmacists or explain their prescription decisions. This might reflect a weak point of the Japanese system.

\subsection{Limitations of the Study}

Although we found that the growth rate was significantly negatively correlated with the expenses of daily former drugs and medical devices per prescription, it was not significantly correlated with the number of drugs and the expenses of daily generic drugs. The possible reasons for these findings are a hypotheses and this research was not able to establish the veracity of them. For settlement the assignment, we must investigate the actions and thoughts of patients, doctors, and pharmacists. This remains for further research.

\section{Acknowledgments}

The all authors have not received financial support and there are not any other interests that could be perceived to bias this work. We would like to thank Editage (www.editage.jp) for English language editing.

\section{Competing Interests Statement}

The authors declare that there is no conflict of interests regarding the publication of this paper. 


\section{References}

Al Rhabi, H. A., Al Sabri, R. M., \& Chitme, H. R. (2014). Interventions by pharmacists in out-patient pharmaceutical care. Saudi Pharmaceutical Journal, 22(2), 101-106. https://doi.org/10.1016/j.jsps.2013.04.001

De Rijdt, T., Willems, L., \& Simoen, S. (2008). Economic effects of clinical pharmacy interventions: a literature review. American Journal of Health-System Pharmacy, 65, 1162-1172. https://doi.org/10.2146/ajhp070506

Japan Pharmaceutical Association. (2011). Separation of pharmacy and clinic progress rate, data for 2011. Retrieved from http://www.nichiyaku.or.jp/contents/bungyo/h23/uke23nendo.pdf

Japan Pharmaceutical Association. (2012). Separation of pharmacy and clinic progress rate, data for 2012.http://www.nichiyaku.or.jp/contents/bungyo/h24/uke24nendo.pdf

Japan Pharmaceutical Association. (2013). Separation of pharmacy and clinic progress rate, data for 2013. Retrieved from http://www.nichiyaku.or.jp/contents/bungyo/h25/2uke25nendo.pdf.

Japan Pharmaceutical Association. (2014). Separation of pharmacy and clinic progress rate, data for 2014. Retrieved from http://www.nichiyaku.or.jp/contents/bungyo/h26/s/26sukei.pdf

Japan Pharmaceutical Association. (2015). Separation of pharmacy and clinic progress rate, data for 2015. Retrieved from http://www.nichiyaku.or.jp/contents/bungyo/h27/s/27sukei.pdf

Ministry of Health, Labour and Welfare. (2011). Medical expenses of dispensing medicine, data for 2011. MHLW, Insurance Bureau Security Research Division Retrieved from http://www.mhlw.go.jp/topics/medias/year/11/dl/gaiyo_data.pdf

Ministry of Health, Labour and Welfare. (2012). Medical expenses of dispensing medicine, data for 2012. MHLW, Insurance Bureau Security Research Division. Retrieved from http://www.mhlw.go.jp/topics/medias/year/12/dl/gaiyo_data.pdf

Ministry of Health, Labour and Welfare. (2013). Medical expenses of dispensing medicine, data for 2013. MHLW, Insurance Bureau Security Research Division. Retrieved from http://www.mhlw.go.jp/topics/medias/year/13/dl/gaiyo_data.pdf

Ministry of Health, Labour and Welfare. (2014). Medical expenses of dispensing medicine, data for 2014. MHLW, Insurance Bureau Security Research Division. Retrieved from http://www.mhlw.go.jp/topics/medias/year/14/dl/gaiyo_data.pdf

Ministry of Health, Labour and Welfare. (2015). Medical expenses of dispensing medicine, data for 2015. MHLW, Insurance Bureau Security Research Division. Retrieved fromhttp://www.mhlw.go.jp/topics/medias/year/15/dl/gaiyo_data.pdf

Ministry of Health, Labour and Welfare. (2016).Summery of public price of medication revision, MHLW, Insurance $\quad$ Bureau. $\quad$ Retrieved from http://www.mhlw.go.jp/file/06-Seisakujouhou-12400000-Hokenkyoku/0000114718.pdf

Saokaew, S., Permsuwan, U., Chaiyakunapruk, N., Nathisuwan, S., Sukonthasarn, A., \& Jeanpeerapong, N. (2013). Cost-effectiveness of pharmacist-participated warfarin therapy management in Thailand. Thrombosis Research. 132(4), 437-443. https://doi.org/10.1016/j.thromres.2013.08.019.

Shireman, T. I., \& Svarstad, B. L. (2016). Cost-effectiveness of Wisconsin TEAM model for improving adherence and hypertension control in black patients. $J$ Am Pharm Assoc, 56(4), 389-96. https://doi.org/10.1016/j.japh.2016.03.002.

Touchette, D. R., Doloresco, F., Suda, K. J., Perez, A., Turner, S., Jalundhwala, Y., ... Hoffman, J. M. (2014). Economic evaluations of clinical pharmacy services. Pharmacotherapy. 34(8), 771-793. https://doi.org/10.1002/phar.1414

Yokoi, M., \& Tashiro, T. (2014). Influence of separation of prescription and dispensation of medicine on its cost in Japanese prefectures. Global Journal of Health Science, 6, 57-62. https://doi.org/10.5539/gjhs.v6n4p57.

Yokoi, M., \& Tashiro, T. (2015). Prescription, dispensation, and generic medicine replacement ratios: Influence on Japanese medicine costs. Global Journal of Health Science, 8, 29-35. https://doi.org/10.5539/gjhs.v8n1p29

Yokoi, M., \& Tashiro, T. (2016). Japanese Community Pharmacists' Dispensing Influences Medicine Price Reduction more than Prescription Numbers. Global Journal of Health Science, 8(9), 20-25. 
https://doi.org/10.5539/gjhs.v8n9p20

\section{Copyrights}

Copyright for this article is retained by the author(s), with first publication rights granted to the journal.

This is an open-access article distributed under the terms and conditions of the Creative Commons Attribution license (http://creativecommons.org/licenses/by/4.0/). 